\title{
The short-term effect of therapeutic exercises (TE) in adolescent idiopathic scoliosis (AIS) evaluated by the BACES system Caterina Cisotti ${ }^{* 1}$, C Volpatti ${ }^{1}$, F D'Osualdo ${ }^{2}$ and S Schierano ${ }^{2}$
}

Address: ${ }^{1}$ Corso di Laurea in Fisioterapia, Facoltà di Medicina, Università degli Studi di Udine, Italy and ${ }^{2}$ Riabilitazione Patologie ad Esordio Infantile, IMFR, ASS n 4 "Medio Friuli", Udine, Italy

* Corresponding author

from $5^{\text {th }}$ International Conference on Conservative Management of Spinal Deformities

Athens, Greece. 3-5 April 2008

Published: 15 January 2009

Scoliosis 2009, 4(Suppl I):O30 doi:I0.II86/I748-7|6I-4-SI-O30

This abstract is available from: http://www.scoliosisjournal.com/content/4/SI/O30

(C) 2009 Cisotti et al; licensee BioMed Central Ltd.

\section{Introduction}

Therapeutic exercises contribute to reduce signs and symptoms of AIS, although their relevance in scoliosis management is still under debate. Scientific literature shows a wide variety of exercises.

\section{Aim}

The goal of our presentation is to illustrate the short-term effects of a few exercises for AIS and to suggest some methodological considerations.

\section{Materials and methods}

Ten female adolescents affected by AIS (moderate severity; mean age: 12,9 years) were enrolled. The short-term effects of 3 exercises (self-elongation, kyphotisation, side-shift) were evaluated, during standing and sitting, in comparison to their own spontaneous posture. Cobb angle of kyphosis and lordosis, ATR, plumb alignment were measured with the BACES system. Exercises were considered effective if the differences of the alignment of the spine were statistically significant when compared with spontaneous posture data. Distribution of frequencies was performed to show the results.

\section{Results}

The effect of therapeutic exercises is characterized by a very high variability among patients. Standing position guarantees a better correction of scoliotic deformity than sitting. Side-shift exercises improve scoliotic deformity in the major part of patients.

\section{Discussion}

It is feasible to verify the short-term efficacy of exercises with surface methods. The effect is often unpredictable, with a lot of variability. Among our exercises, the sideshift exercise seems to be the more effective in reducing both side translation and rotation of the back, especially while standing.

\section{Conclusion}

Considering the unpredictable effects, every exercise should be tested before being prescribed.

\section{References}

I. Dickson RA: Spinal Deformity - Adolescent Idiopathic Scoliosis. Nonoperative treatment. Spine 1999, 24(24):260I-2606.

2. Rigo $M$, et al: International conference on conservative management of spinal deformities (Barcelona 2004). Paediatric Rehabilitation 2004, 7:5I-64.

3. Maruyama T, Kitagawa T, Takeshita K, Mochizuki K, Nakamura K: Conservative treatment for adolescent idiopathic scoliosis: can it reduce the incidence of surgical treatment? Paediatric Rehabilitation 2003, 6:215-219. 